\title{
Structural Analysis of Thermally-Annealed Bulk Heterojunction Films Based on Sexithiophene and Fullerene
}

\author{
Yosei Shibata $^{1,2}$, Takahiro Kono', Takahiko Suzuki², Yuzuru Narita² ${ }^{2}$ Fumihiko Hirose $^{2}$, \\ Yuji Yoshida $^{*}$ \\ ${ }^{1}$ Research Center for Photovoltaic Technologies, National Institute of Advanced Industrial Science and \\ Technology, Tsukuba, Japan \\ ${ }^{2}$ Graduate School of Science and Engineering, Yamagata University, Yonezawa, Japan \\ Email: yuji.yoshida@aist.go.jp
}

Received 25 April 2014; revised 5 June 2014; accepted 23 June 2014

Copyright (C 2014 by authors and Scientific Research Publishing Inc.

This work is licensed under the Creative Commons Attribution International License (CC BY).

http://creativecommons.org/licenses/by/4.0/

(c) $\underset{\mathrm{EY}}{\mathrm{i}}$ Open Access

\section{Abstract}

Recently, power conversion efficiencies of organic photovoltaics based on small molecules have been dramatically improved by means of the bulk heterojunction (BHJ) structure. Moreover, to optimize photovoltaic performance, thermal annealing treatments have often been used because of the simplicity of the process. However, the elucidation of effects of thermal annealing treatment on BHJ film structure based on small molecules is still not enough. Here, we report the results of structural analysis with synchrotron radiation of $\alpha$-sexithiophene:fullerene BHJ films before and after thermal annealing treatment. In particular, the open-circuit voltage was increased to as high as $0.72 \mathrm{~V}$; moreover, the BHJ films based on $\alpha$-sexithiophene and fullerene were also clearly crystallized by the thermal annealing treatment. In this study, we found that the optimal crystal size existed in BHJ films for high-performance organic photovoltaics.

\section{Keywords}

Organic Photovoltaics, Oligothiophene, Bulk Heterojunction Structure, Thermal Anneal, Morphological Control

\section{Introduction}

Organic photovoltaics (OPV) have received considerable attention because of their numerous potential advantages including flexibility, low cost and colorful photovoltaic devices. OPV's efficiency of converting sun-light

\footnotetext{
*Corresponding author.
}

How to cite this paper: Shibata, Y., Kono, T., Suzuki, T., Narita, Y., Hirose, F. and Yoshida, Y. (2014) Structural Analysis of Thermally-Annealed Bulk Heterojunction Films Based on Sexithiophene and Fullerene. Advances in Materials Physics and Chemistry, 4, 127-133. http://dx.doi.org/10.4236/ampc.2014.47015 
to electrical energy was drastically improved by development of the bulk heterojunction (BHJ) structure in 1991, which is fabricated by co-deposition method [1]. Organic semiconductors are well known to have very short exciton diffusion length. The concept of the BHJ structure is based on extension of interface area between donor and acceptor in the active layer. Because of its ability to achieve an efficient exciton (electron-hole binding pair) dissociation rate, the BHJ structure is very useful for generating high photocurrent. To facilitate the realization of high-performance BHJ-type devices, thermal annealing treatments have been investigated extensively [2]-[6]. The treatment of solution-processed BHJ film based on polymer and fullerene derivatives leads to improvement of photovoltaic performance due to many advantages such as removal of organic solvent in their preparation [7] and, the phase separation effect between donor and acceptor [8] [9]. These effects arise from the high thermal reactivity of polymer used in the films, such as their low glass transition temperature and melting point [10].

On the other hand, the BHJ-type OPV devices based on small molecules have been investigated with co-deposition method [11]-[15]. As a candidate of donor materials, oligothiophene has been investigated due to high carrier mobility, deep HOMO level and controllable energy level through easy chemical modification. These factors promise high open-circuit voltage $\left(V_{\text {oc }}\right)$. In particular, $\alpha$-sexithiophene (6T) molecules were also used as organic field-effect transistor because of their highly-ordered crystalline structure [16] [17]. High $V_{\text {oc }}$ in oligothiophene:fullerene $=1: 5$ co-deposited devices, about $0.6 \mathrm{~V}$ with fullerene $\mathrm{C}_{70}$, has been already reported [18]. These results are attributed to deep HOMO level $(5.2 \mathrm{eV})$ and suppression of aggregated $\alpha-6 \mathrm{~T}$ molecules. Furthermore, to enhance the power conversion efficiency, thermal annealing treatment of fullerene-rich BHJ-type devices based on $\alpha$-6T and fullerene has been reported [19]. However, the effects of thermal annealing treatments on BHJ films based on small molecules remain unclear. Improvement of photovoltaic performance based on small molecules subjected to thermal annealing treatment requires elucidation of structural analysis of BHJ layer.

Here-in, to elucidate the thermal annealing effects on BHJ films including $\alpha$-sexithiophene and fullerene molecules, we focused on morphology in oligothiophene: $\mathrm{C}_{60}$ co-deposited films. In this study, we investigated the effects of thermal annealing effects on BHJ films based on oligothiphene and fullerene $\mathrm{C}_{60}$.

\section{Experimental}

\subsection{Device Fabrication}

The OPV devices were fabricated using a vacuum deposition system (EO-5, Eiko Engineering Co., Ltd.) at a pressure of $10^{-4} \mathrm{~Pa}$ which was connected to $\mathrm{N}_{2}$-filled glove box. Sexithiophene (sublimed grade, purchased from Tokyo Chemical Industry Co., Ltd.) and $\mathrm{C}_{60}$ (purity of 99\%, purchased from MTR. Ltd.), were further purified by vacuum sublimation prior to deposition. The procedures of device fabrication are as follows. First, glass substrates coated indium-tin-oxide (ITO, purchased from Sanyo Vacuum Industry Co., Ltd.) were cleaned with oxygen plasma for $30 \mathrm{~min}$. The thickness of ITO films was $150 \mathrm{~nm}$, and their sheet resistance was less than 15 $\Omega / \square$. Next, poly(3,4-ethylenedioxylenethiophene):polystyrene sulfuric acid blend solution (PEDOT:PSS, Clevious $^{\mathrm{TM}}$ PVP Al 4083) was coated with spin-coating method as an electron blocking layer in ambient air. The ITO substrates coated with PEDOT:PSS was subsequently dried for $10 \mathrm{~min}$ at $135^{\circ} \mathrm{C}$ in order to remove moisture. This substrate was transferred to a vacuum chamber via $\mathrm{N}_{2}$-filled globe box. Here, a $6 \mathrm{~T}: \mathrm{C}_{60}=1: 5$ co-deposition layer with a thickness of $50 \mathrm{~nm}$, a bathocuproine (BCP, purchased from Dojindo Co., Ltd.) with a thickness of $6 \mathrm{~nm}$ and an Aluminum electrode with a thickness of $100 \mathrm{~nm}$ were deposited sequentially. The volume ratio in the $6 \mathrm{~T}: \mathrm{C}_{60}$ co-deposited films were controlled by deposition rate: $6 \mathrm{~T}$ and $\mathrm{C}_{60}$ were deposited at 0.01 $\mathrm{nm} / \mathrm{s}$ and $0.05 \mathrm{~nm} / \mathrm{s}$, respectively. The deposition rate of $6 \mathrm{~T}$ and $\mathrm{C}_{60}$ was monitored by two separate quartz crystal microbalances. Thermal annealing of fabricated devices (post-annealing) were treated with hot plate under controlled temperature in $\mathrm{N}_{2}$-filled globe box. To observe the effects of changes in the annealing temperature, we increased the annealing temperature stepwise from $100^{\circ} \mathrm{C}, 120^{\circ} \mathrm{C}$, and $130^{\circ} \mathrm{C}$, sequentially. The devices were heated devices for $10 \mathrm{~min}$, and then allowed to cool for over $10 \mathrm{~min}$ at room temperature in each step, as shown in Figure 1.

\subsection{Measurement}

$J$ - $V$ characteristics were measured using a source meter (KEITHLEY 2400 series, Keithley Instruments Inc.) and an air mass $1.5 \mathrm{G}$ simulated solar light source at a power density of $100 \mathrm{~mW} / \mathrm{cm}^{2}$; the light source was calibrated using a Si-photodiode (Bunkokeiki Co., Ltd.). The surface morphology of oligothiophene: $\mathrm{C}_{60}=1: 5$ co-deposited films was analyzed using a field-emission scanning electron microscope (FE-SEM: S-4800, Hitachi Hi-tech 


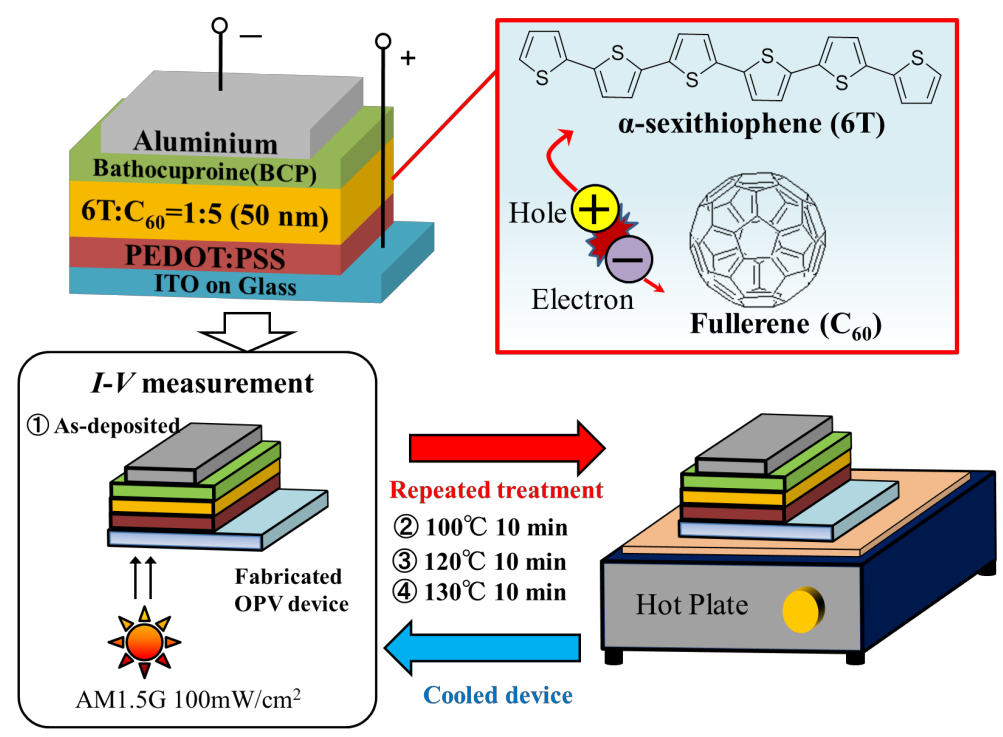

Figure 1. Schematic of a fabricated OPV device during thermal annealing process and chemical structures.

Inc.) operated at an acceleration voltage of $5 \mathrm{kV}$. The crystallinity of the films was investigated by X-ray diffraction measurement system using synchrotron radiationbeam line of wavelength $0.10 \mathrm{~nm}$ at SPring-8 in Japan. Co-deposited samples with no aluminum electrode were deposited on $\mathrm{SiO}_{2}$ substrate coated with PEDOT:PSS layer for the FE-SEM and XRD measurement. To improve surface wettability of $\mathrm{SiO}_{2}$ substrate, UV-ozone treatment for 30 min before being spin-coated with PEDOT:PSS.

\section{Results and Discussion}

\subsection{OPV Performance of the 6T: $\mathrm{C}_{60}$ Devices}

Figure 2 and Table 1 show the dependence of the $J$ - $V$ plots on the thermal annealing temperature and the photovoltaic parameters estimated from these plots, respectively. The power conversion efficiency (PCE) improved from $1 \%$ for the as-deposited device to $1.4 \%$ at after the annealing treatment. The enhancement of the PCEs strongly depends on the improvement of short-circuit current density $\left(J_{\mathrm{sc}}\right)$ and open-circuit voltage $\left(V_{\mathrm{oc}}\right)$. Fill factor $(F F)$ values were approximately same despite of thermal annealing treatments. Generally, $F F$ of photovoltaic device is influenced by its internal resistance of photovoltaic device [20]. In contrast to the $F F$ values, series resistance $\left(R_{\mathrm{s}}\right)$ and parallel $\left(R_{\mathrm{p}}\right)$ resistance are improved, which indicates that the thermal annealing process improved the carrier transportation and suppressed leak current. In this study, there are not relationship between constant of $F F$ value and improvement of internal resistance, clearly. Hirade and Adachi have reported that exciton dissociation rate at interface between electrode and active layer strongly depends on FF [21] [22]. Therefore, enhancement of PCEs by thermal annealing is attributed to structural change of $\alpha-6 \mathrm{~T}: \mathrm{C}_{60}$ co-deposited films rather than interface between electrode and co-deposited films. In next section, we focused on the morphological analysis of $6 \mathrm{~T}: \mathrm{C}_{60}=1: 5$ co-deposited films.

\subsection{Morphology and Crystal Structure of the 6T: $\mathrm{C}_{60}$ Films}

In Section 3.1, the photovoltaic performance of the BHJ-type devices was demonstrated to be improved by the thermal annealing treatments. To clarify the effects of these treatments, we investigated the structure of as deposited $\alpha-6 \mathrm{~T}: \mathrm{C}_{60}=1: 5$ films and the film annealed at $130^{\circ} \mathrm{C}$. Figure 3 shows SEM images of $\alpha-6 \mathrm{~T}: \mathrm{C}_{60}=1: 5$ co-deposited films. With respect to the surface morphology, many aggregates, which are expressed by regions of white contrast, disappeared. In addition, size of aggregates when annealed at $130^{\circ} \mathrm{C}$ was larger than those in as-deposited condition. This fibril-like structure (indicated by red circles in Figure 3(c)) is aggregates of $\alpha$-6T molecules [18]. Some grains were observed in the cross-sectional images of the $\alpha-6 \mathrm{~T}: \mathrm{C}_{60}=1: 5$ co-deposited films before they were subjected to thermal annealing treatment, as shown in Figure 3(c). After the films were 


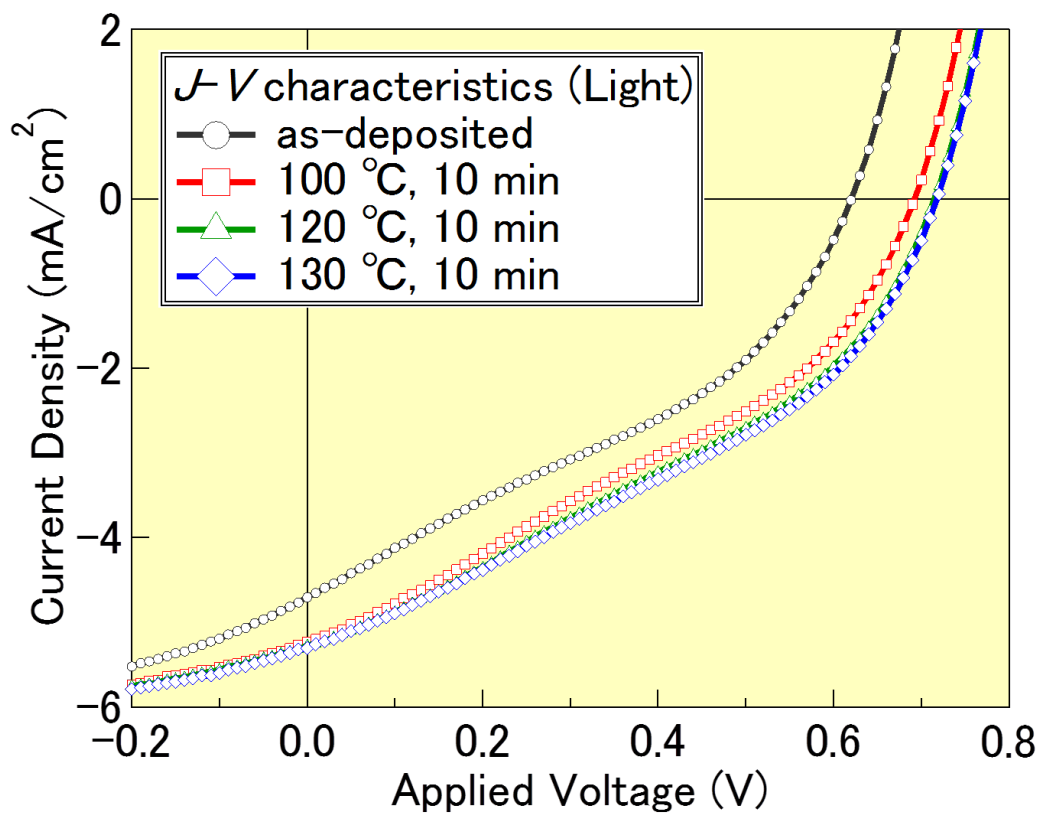

Figure 2. $J-V$ characteristics under sunlight exposure with a spectrum of AM 1.5 $\mathrm{G}$ and power density of $100 \mathrm{~mW} / \mathrm{cm}^{2}$ for ITO/PEDOT:PSS/6T: $\mathrm{C}_{60}=1: 5(50 \mathrm{~nm}) /$ $\mathrm{BCP}(6 \mathrm{~nm}) / \mathrm{Al}(100 \mathrm{~nm})$.
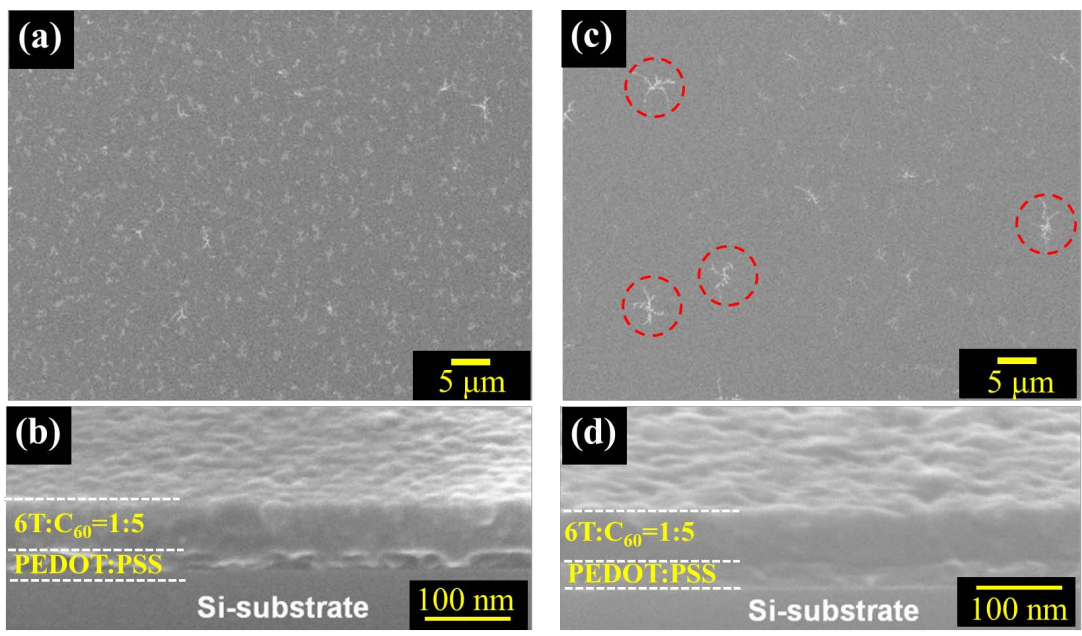

Figure 3. SEM images of 6T: $\mathrm{C}_{60}=1: 5$ film surfaces on $\mathrm{SiO}_{2} /$ PEDOT:PSS substrates: (a) As-deposited film surface; (b) Cross-sectional image of as-deposited film; (c) Surface image after annealed $130^{\circ} \mathrm{C}$ for $10 \mathrm{~min}$ (inset: red circles indicate aggregation of $6 \mathrm{~T})$; and (d) Cross-sectional image of the film represented image (c).

Table 1. Performance parameters for ITO/PEDOT:PSS/6T:C $60=1: 5(50 \mathrm{~nm}) / \mathrm{BCP}(6 \mathrm{~nm}) / \mathrm{Al}(100 \mathrm{~nm})$ devices.

\begin{tabular}{ccccccc}
\hline $\begin{array}{c}\text { Temperature } \\
\left({ }^{\circ} \mathrm{C}\right)\end{array}$ & PCE (\%) & $J_{\mathrm{sc}}\left(\mathrm{mA} / \mathrm{cm}^{2}\right)$ & $V_{\text {oc }}(\mathrm{V})$ & $\begin{array}{c}\text { Fill } \\
\text { Factor }\end{array}$ & $R_{\mathrm{s}}\left(\Omega \cdot \mathrm{cm}^{2}\right)$ & $R_{\mathrm{p}}\left(\mathrm{k} \Omega \cdot \mathrm{cm}^{2}\right)$ \\
\hline As-Deposited & 1.04 & 4.70 & 0.62 & 0.36 & 47.3 & 0.17 \\
100 & 1.26 & 5.23 & 0.69 & 0.35 & 42.6 & 0.22 \\
120 & 1.35 & 5.27 & 0.71 & 0.36 & 42.7 & 0.26 \\
130 & 1.37 & 5.25 & 0.72 & 0.36 & 37.9 & 0.26 \\
\hline
\end{tabular}


annealed, grains observed in the images of the as-deposited films disappeared. In the SEM images, contrast was changed according to different crystal planes being observed. Then, we measured X-ray diffraction with synchrotron irradiation. Figure 4 shows in-plane diffraction patterns of $\alpha-6 \mathrm{~T}: \mathrm{C}_{60}=1: 5$ co-deposited films with $2 \theta \chi / \varphi$ mode. To assign components and crystal planes in these patterns, we also show in-plane diffraction patterns of as-deposited $\mathrm{C}_{60}$ single-component film. Out-of-plane diffraction was not observed for any BHJ films. Scattering vector $\boldsymbol{Q}$ was calculated by following Equation (1).

$$
|Q|=\frac{4 \pi}{\lambda} \sin \theta
$$

where $\lambda$ and $\theta$ are wavelength of incident $\mathrm{X}$-ray beam and diffraction angle that satisfies Bragg's equation, respectively. The (022), (113), (224) and (333) planes of as-deposited film did not diffract, indicating that the single-component $\mathrm{C}_{60}$ film had face-centered-cubic lattice structure [23]. This result means that crystallization of fullerene was prevented from presence of $\alpha-6 \mathrm{~T}$. In this study, compositional ratio of $\mathrm{C}_{60}$ is higher than that of $\alpha-6 \mathrm{~T}$. We suggest that preferential crystal growth of donor or acceptor molecules during the co-deposition is dominated by the blend ratio. After being subjected to thermal annealing treatment, co-deposited film exhibited diffraction peaks similar to those of single-component $\mathrm{C}_{60}$ film. Therefore, thermal annealing treatment leads to crystallization of BHJ films based on oligothiophene and fullerene $\mathrm{C}_{60}$. Moreover, a new peak appeared at $Q=$ $1.59 \AA^{-1}$ (a black triangle shown in Figure 4). This scattering vector value corresponds to d-spacing of $3.95 \AA$. This peak corresponds to $\pi$-stacking structure of oligothiophene when that was standing on substrate [24]. These results suggest that fibril-like aggregation structure shown in SEM image has crystalline phase. Thermal annealing treatment clearly leads to structural change of oligothiophene: $\mathrm{C}_{60}$ co-deposited films and improvement of $J_{\mathrm{sc}}$ and $V_{\mathrm{oc}}$. The melting points and transition temperature of $\alpha-6 \mathrm{~T}$ and $\mathrm{C}_{60}$ molecules has no temperature region within annealing temperature from $100^{\circ} \mathrm{C}$ to $130^{\circ} \mathrm{C}$ [25]. Morphological change of co-deposited films occurred irrespective of these thermal reactivity. Small molecules showed coherent trend with thermal treatment. Moreover, morphology and crystal structure was drastically changed by thermal annealing treatments. Indeed, device performance with $6 \mathrm{~T}: \mathrm{C}_{60}=1: 5$ co-deposited films were improved. Unchanged $F F$ values despite of annealing treatment might be attributable to crystallization of BCP used as an exciton blocking layer. Therefore, these results indicate that there is the optimal blend morphology and crystal size in BHJ films exist that maximize carrier transport and exciton dissociation efficiency. As one of next challenges, to completely understand thermal annealing effects, investigation of interface between electrode and active layer, including influence of BCP layer, will be necessary.

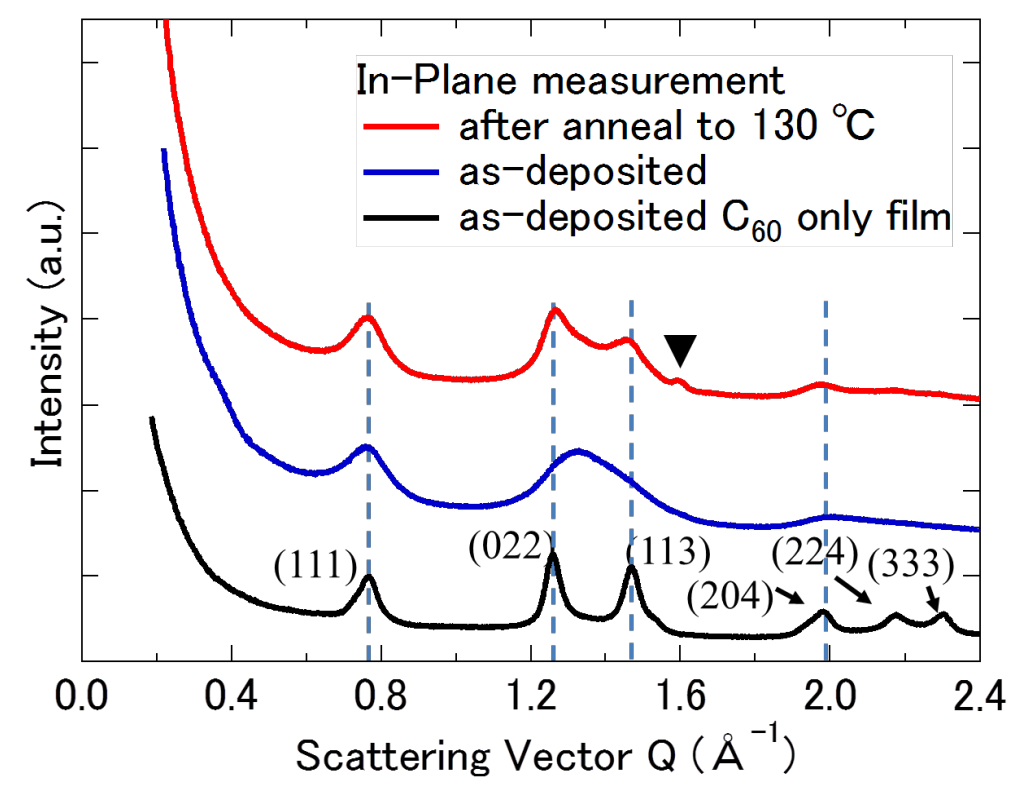

Figure 4. X-ray diffraction patterns (in-plane) of $\alpha-6 \mathrm{~T}: \mathrm{C}_{60}=1: 5(50 \mathrm{~nm})$ codeposited films on $\mathrm{SiO}_{2} / \mathrm{PEDOT}$ :PSS. The solid black line represents the diffraction pattern of a $\mathrm{C}_{60}$ single-component film. 


\section{Conclusion}

In this study, we investigated effects of thermal annealing on morphology of oligothiophene:fullerene blend films and on their photovoltaic performance. The thermal annealing treatment clearly leads to improvement of device performance with these blend films. On the basis of the structural analysis, these effects are attributed to crystallization of both oligothiophene and fullerene molecules. To control the BHJ structure, we demonstrated that thermal annealing method was also useful for BHJ films fabricated by vacuum process.

\section{Acknowledgements}

This work was supported by the Core Research for Evolutional Science and Technology (CREST) of the Japan Science and Technology Agency (JST). Moreover, technical support for the XRD measurements with synchrotron radiation at SPring-8 was provided by Japan Synchrotron Radiation Research Institute (JASRI).

\section{References}

[1] Hiramoto, M., Fujiwara, H. and Yokoyama M. (1991) Three-Layered Organic Solar Cell with a Photoactive Interlayer of Co-Deposited Pigments. Applied Physics Letter, 58, 1062-1064. http://dx.doi.org/10.1063/1.104423

[2] Li, G., Shrotriya, V., Yao, Y. and Yang, Y. (2005) Investigation of Annealing Effects and Film Thickness Dependence of Polymer Solar Cells Based on Poly(3-Hexylthiophene). Journal of Applied Physics, 98, Article ID: 043704. http://dx.doi.org/10.1063/1.2008386

[3] Kim, K., Liu, J., Namboothiry, M.A.G. and Carroll, D.L. (2007) Roles of Donor and Acceptor Nanodomains in 6\% Efficient Thermally Annealed Polymer Photovoltaics. Applied Physics Letter, 90, Article ID: 163511. http://dx.doi.org/10.1063/1.2730756

[4] Al-Ibrahim, M., Ambacher, O., Sensfuss, S. and Gobsch, G. (2005) Effects of Solvent and Annealing on the Improved Performance of Solar Cells Based on Poly(3-Hexylthiophene):Fullerene. Applied Physics Letter, 86, Article ID: 201120. http://dx.doi.org/10.1063/1.1929875

[5] Ayzner, A.L., Wanger, D.D., Tassone, C.J., Tolbert, S.H. and Schwartz, B.J. (2008) Room to Improve Conjugated Polymer-Based Solar Cells: Understanding How Thermal Annealing Affects the Fullerene Component of a Bulk Heterojunction Photovoltaic Device. Journal of Physical Chemistry C, 112, 18711-18716. http://dx.doi.org/10.1021/jp8076497

[6] Padinger, F., Rittberger, R.S. and Sariciftci, N.S. (2003) Effects of Postproduction Treatment on Plastic Solar Cells. Advanced Functional Materials, 13, 85-88. http://dx.doi.org/10.1002/adfm.200390011

[7] Rezvani, M.H., Farajollahi, F., Nikfarjam, A., Bakhtiarpour, P. and Saydanzad, E. (2003) Effect of Solvents, Their Mixture and Thermal Annealing on the Performance of Solution Processed Polymer Light-Emitting Diodes. Materials, 6, 1994-2006. http://dx.doi.org/10.3390/ma6051994

[8] Yang, X., Loos, J., Veenstra, S.C., Verhees, W.J.H., Wienk, M.M., Kroon, J.M., Michels, M.A.J. and Janssen, R.A.J. (2005) Nanoscale Morphology of High-Performance Polymer Solar Cells. Nano Letters, 5, 579-583. http://dx.doi.org/10.1021/nl048120i

[9] Hoppe, H., Niggemann, M., Winder, C., Kraut, J., Hiesgn, R., Hinsch, A., Meissner, D. and Sariciftci, N.S. (2004) Nanoscale Morphology of Conjugated Polymer/Fullerene-Based Bulk-Heterojunction Solar Cells. Advanced Functional Materials, 14, 1005-1011. http://dx.doi.org/10.1002/adfm.200305026

[10] Zhao, Y., Yuan, G.X., Roche, P. and Leclerc, M. (1995) A Calorimetric Study of the Phase Transitions in Poly(3-Hexylthiophene). Polymer, 36, 2211. http://dx.doi.org/10.1016/0032-3861(95)95298-F

[11] Noh, S., Kim, S., Yang, J. and Lee, C. (2008) Investigation into the Thermal Annealing Effect on the Photovoltaic Properties of Organic Solar Cells Based on $\mathrm{CuPc} / \mathrm{C}_{60}$ Heterojunctions. Journal of the Korean Physical Society, 53, 1551-1555. http://dx.doi.org/10.3938/jkps.53.1551

[12] Taima, T., Toyoshima, S., Hara, K., Saito, K. and Yase, K. (2006) Realization of Large Open-Circuit Photovoltage in Organic Thin-Film Solar Cells by Controlling Measurement Environment. Japanese Journal of Applied Physics, 45, L217-L219. http://dx.doi.org/10.1143/JJAP.45.L217

[13] Iketaki, K., Kaji, T., Nakao, S. and Hiramoto, M. (2011) Structural Studies of the Co-Depositedi-Layer of ZnPc: $\mathrm{C}_{60} \mathrm{P}-\mathrm{i}-$ n Solar cells. Physica Status Solidi C, 8, 637-639. http://dx.doi.org/10.1002/pssc.201000462

[14] Sakai, J., Taima, T., Yamanari, T., Yoshida, Y., Fujii, A. and Ozaki, M. (2010) Pentacene:Fullerene Multilayer-Heterojunction Organic Photovoltaic Cell Fabricated by Alternating Evaporation Method. Japanese Journal of Applied Physics, 49, Article ID: 032301. http://dx.doi.org/10.1143/JJAP.49.032301

[15] Pfuetzner, S., Mickel, C., Jankowski, J., Hein, M., Meiss, J., Schuenemann, C., Elschner, C., Levin, A.A., Rellinghaus, 
B., Leo, K. and Riede, M. (2011) The Influence of Substrate Heating on Morphology and Layer Growth in $\mathrm{C}_{60}: \mathrm{ZnPc}_{\mathrm{B}}$ Bulk Heterojunction Solar Cells. Organic Electronics, 12, 435-441. http://dx.doi.org/10.1016/j.orgel.2010.12.007

[16] Dodabalapur, A., Torsi, L. and Katz, H.E. (1995) Organic Transistors: Two-Dimensional Transport and Improved Electrical Characteristics. Science, 268, 270. http://dx.doi.org/10.1126/science.268.5208.270

[17] Horowitz, G., Garnier, F., Yassar, A., Hajlaoui, R. and Kouki, F. (1996) Field-Effect Transistor Made with a Sexithiophene Single Crystal. Advanced Material, 8, 52-54. http://dx.doi.org/10.1002/adma.19960080109

[18] Sakai, J., Taima, T., Yamanari, T. and Saito, K. (2008) Efficient Oligothiophene:Fullerene Bulk Heterojunction Organic Photovoltaic Cells. Organic Electronics, 9, 582-590. http://dx.doi.org/10.1016/j.orgel.2008.03.008

[19] Sakai, J., Taima, T., Yamanari, T. and Saito, K. (2009) Annealing Effect in the Sexithiophene:C ${ }_{70}$ Small Molecule Bulk Heterojunction Organic Photovoltaic Cells. Solar Energy Materials \& Solar Cells, 93, 1149-1153. http://dx.doi.org/10.1016/j.solmat.2009.02.007

[20] Hoshikawa, T., Yamada, M., Kikuchi, R. and Eguchi, K. (2005) Impedance Analysis of Internal Resistance Affecting the Photoelectrochemical Performance of Dye-Sensitized Solar Cells. Journal of the Electrochemical Society, 152, E68-E73. http://dx.doi.org/10.1149/1.1849776

[21] Kim, M.-S., Kim, B.-G. and Kim, J. (2009) Effective Variables to Control the Fill Factor of Organic Photovoltaic Cells. Applied Materials and Interfaces, 1, 1264-1269. http://dx.doi.org/10.1021/am900155y

[22] Hirade, M. and Adachi, C. (2011) Small Molecular Organic Photovoltaic Cells with Exciton Blocking Layer at Anode Interface for Improved Device Performance. Applied Physics Letter, 99, 153302. http://dx.doi.org/10.1063/1.3650472

[23] Skokan, E.V., Arkhangelskii, I.V., Izotov, D.E., Chelovskaya, N.V., Nikulin, M.M. and Velikodnyi, Y.A. (2005) Stability of Hexagonal Modification of Fullerite $\mathrm{C}_{60}$. Carbon, 43, 803-808. http://dx.doi.org/10.1016/j.carbon.2004.11.007

[24] Shibata, Y., Kono, T., Komura, N. and Yoshida, Y. (2013) Structural Control of Bulk Heterojunction Films Based on Oligothiophene with Sterically-Bulky Groups. Organic Electronics, 14, 1073-1080. http://dx.doi.org/10.1016/j.orgel.2013.01.015

[25] Sasaki, K., Shibata, Y., Lu, M., Yoshida, Y., Azumi, R. and Ueda, Y. (2013) Effect of Side Chain of Oligothiophene Derivatives on Bulk Heterojunction Structure in Organic Photovoltaic Devices. Advances in Materials Physics and Chemistry, 3, 185-190. http://dx.doi.org/10.4236/ampc.2013.32026 
Scientific Research Publishing (SCIRP) is one of the largest Open Access journal publishers. It is currently publishing more than 200 open access, online, peer-reviewed journals covering a wide range of academic disciplines. SCIRP serves the worldwide academic communities and contributes to the progress and application of science with its publication.

Other selected journals from SCIRP are listed as below. Submit your manuscript to us via either submit@scirp.org or Online Submission Portal.
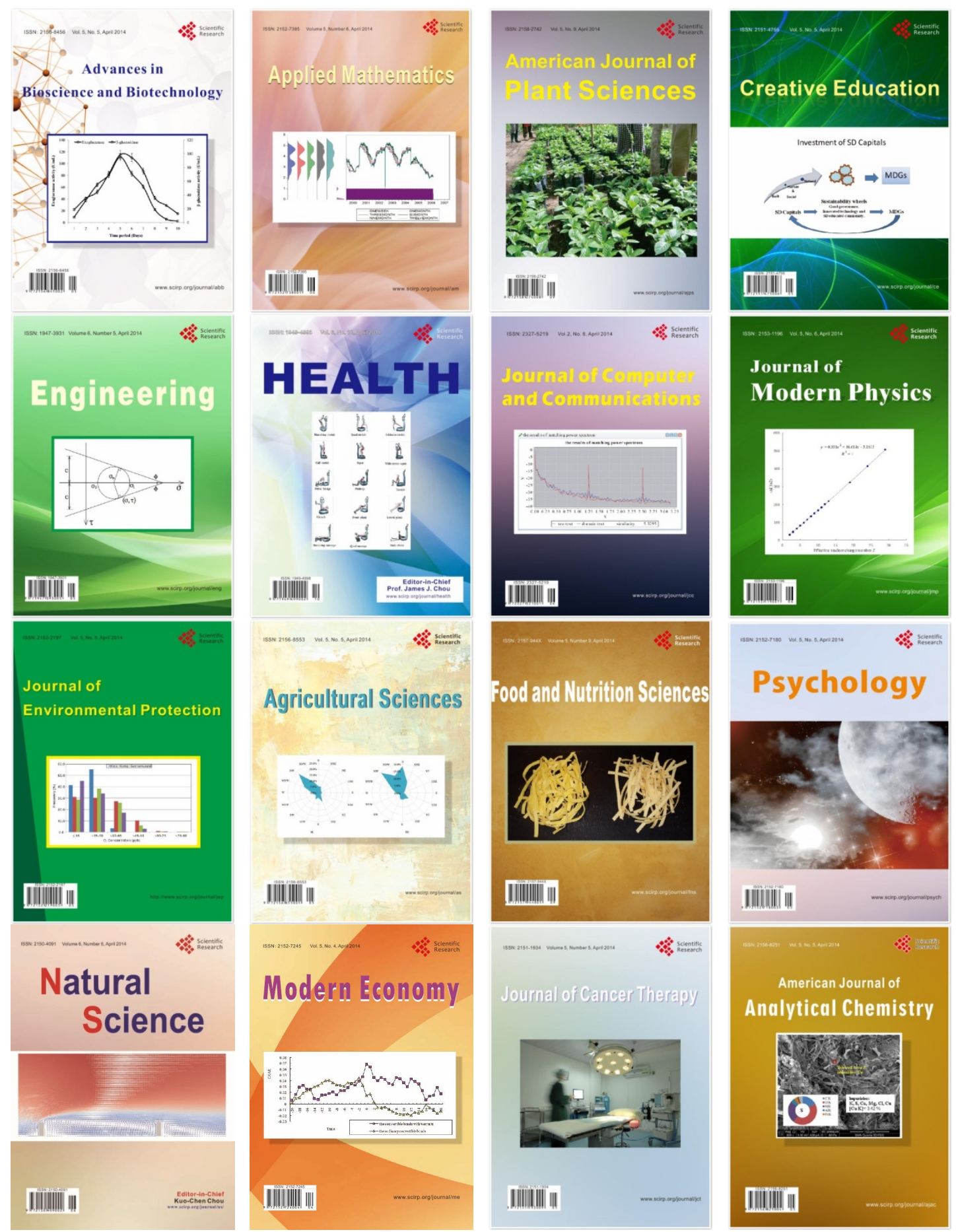